\title{
Forest Cover Change within the Russian European North after the Breakdown of Soviet Union (1990-2005)
}

\author{
Peter Potapov, ${ }^{1}$ Svetlana Turubanova, ${ }^{1}$ Ilona Zhuravleva, ${ }^{2}$ Matthew Hansen, ${ }^{1}$ \\ Alexey Yaroshenko, ${ }^{2}$ and Alexander Manisha ${ }^{2}$ \\ ${ }^{1}$ Department of Geographical Sciences, University of Maryland, College Park, MD 20742, USA \\ ${ }^{2}$ Greenpeace Russia, Leningradsky prospekt 26/1, 125040 Moscow, Russia
}

Correspondence should be addressed to Peter Potapov, potapov@umd.edu

Received 22 December 2011; Accepted 28 February 2012

Academic Editor: Harri Mäkinen

Copyright () 2012 Peter Potapov et al. This is an open access article distributed under the Creative Commons Attribution License, which permits unrestricted use, distribution, and reproduction in any medium, provided the original work is properly cited.

\begin{abstract}
Forest cover dynamics (defined as tree canopy cover change without regard to forest land use) within the Russian European North have been analyzed from 1990 to 2005 using a combination of results from two Landsat-based forest cover monitoring projects: 1990-2000 and 2000-2005. Results of the forest cover dynamics analysis highlighted several trends in forest cover change since the breakdown of the Soviet planned economy. While total logging area decreased from the 1990-2000 to the 2000-2005 interval, logging and other forms of anthropogenically-induced clearing increased within the Central and Western parts of the region. The most populated regions of European Russia featured the highest rates of net forest cover loss. Our results also revealed intensive gross forest cover loss due to forest felling close to the Russian-Finland border. The annual burned forest area almost doubled between the two time intervals. The 2000-2005 gross forest cover gain results suggest that tree encroachment on abandoned agriculture land is a wide-spread process over the region. The analysis demonstrates the value of regional-scale Landsat-based forest cover and change quantification. Our results supplemented official data by providing independently derived spatial information that could be used for assessing on-going trends and serve as a baseline for future forest cover monitoring.
\end{abstract}

\section{Introduction}

The European part of Russia spans over $40 \%$ of the European subcontinent and contains about $23 \%$ of Russia's land area. The region plays a key role in national timber production as a source of $55 \%$ of harvested roundwood, more than $55 \%$ of sawn wood, $82 \%$ of veneer, and $98 \%$ of paper [1]. Forests of the European part of the country experienced the highest rates of anthropogenic disturbance, especially in the regions with intensive timber harvesting, high population density, as well as in agriculture regions where remaining forest patches are fragmented by croplands. Forest harvesting and timber processing are located principally in the Russian European North within 20 administrative regions, including Arkhangelsk, Ivanovo, Kirov, Kostroma, Leningrad, Moscow, Murmansk, Nizhny Novgorod, Novgorod, Pskov, Tver, Vladimir, Vologda, Yaroslavl Oblast, Chuvash, MariEl, Karelia, Komi, Udmurt Republic, and Perm Kray. These regions include almost $84 \%$ of European Russia's forest area and produced about $50 \%$ of total timber harvested within the country in the year 2005 [1].

Due to the long history of human interaction with forest landscapes in Europe, the current forest structure and dynamics in the region are significantly altered by anthropogenic factors [2]. These include (i) alteration of tree species composition and population structure by forest management practices; (ii) forest fragmentation by agriculture clearings, roads and settlements; (iii) changes in natural forest dynamic processes. In the Russian European North, where forests are actively used for timber production, timber harvesting (especially in the form of clear-cuts) and humaninduced forest fires are the key components of current standlevel forest dynamics. Forest stand rotation length (time from the establishment of a forest stand to its final felling) and fire return interval have been shown to be important factors regulating carbon stock and carbon exchange in managed forests $[3,4]$. 
Given these dynamics, periodic forest cover monitoring is required for carbon balance estimation and sustainable forest management assessments. However, existing national scale forest area statistics are incomplete and inconsistent. Russian official forest inventory data were provided by the Federal Forest Agency at 5-year intervals [5]. These data summarize information at regional scales based on stepwise data integration from detailed forest unit maps and databases. The forest units are subject to a detailed ground survey every 10-12 years. However, the frequency and quality of forest inventory data within unmanaged remote areas of Northern Russia are lower when compared to those of central regions [6]. The official forest inventory data lack annual forest cover change information, for example, annual forest harvesting area. Burned area estimates for Russia vary by an order of magnitude, depending on the data source [7]. Another problem concerning the Russian forest inventory data is its restricted public access [8]. In 2006, Russia introduced new forest legislation that resulted in substantial changes to the forest inventory and statistics system, exacerbating the ability to compare dynamics in the recent past [9]. According to the current forest legislation, the Russian Federal Forest Agency is responsible for providing National Forest Inventory (NFI) and periodic publication of forest statistic data. However, the official document on NFI methodology was issued by the Forest Agency only on June 6, 2011 (executive order number 207), and no new comprehensive analysis of forest resources has been published since 2003.

Satellite remotely sensed data provide a practical and comparatively inexpensive solution for periodic monitoring of forest cover at the regional scale. An additional advantage of satellite-based monitoring is its independence from official national forest management agencies, enabling the immediate release of results to science, conservation, and general public communities. From all available sources of satellite data, Landsat imagery stands out as the only dataset with global coverage for a sequence of sensors with similar spectral and spatial resolutions. The relatively high spatial resolution of Landsat TM/ETM+ sensors allows for accurate forest cover change area estimation, as well as disaggregation of the estimates per administrative regions [10]. However, the use of Landsat data for regional-scale monitoring has been limited until recently due to high data costs. The first region-wide satellite-based assessment of forest cover change for the European Russia was performed by the nongovernmental organization Greenpeace [11] for the 1990-2000 time interval using freely available imagery and data purchased by Greenpeace. In January 2008, the U.S. Geological Survey (USGS) implemented a new Landsat Data Distribution Policy that provides Landsat data free of charge [12]. Recent progress in automatic Landsat data processing and mosaicing to produce cloud-free annual or epochal composite images $[13,14]$ opened the possibility for Landsat-based monitoring over large regions. Lately, an approach for regional-scale forest monitoring using mass-processing of the Landsat archive data has been developed [15]. The approach was implemented to estimate forest cover area and change from 2000 to 2005 within European Russia. The regional-scale forest cover and change maps can be viewed and downloaded from the following dedicated web sites: http://forestforum.ru (for 1990-2000 monitoring results) and http//globalmonitoring.sdstate.edu/projects/boreal/ (for year 2000 forest cover and 2000-2005 monitoring results).

While regional-scale forest cover change analyses provided by Greenpeace [11] and Potapov et al. [15] were based on different classification techniques, they are comparable as they both use the same data source (Landsat imagery) and the same forest cover and forest cover loss definitions. The forest cover definition is based on land cover classification without regard to forest land use. Forest cover was defined as areas with at least $25 \%$ tree canopy density within Landsat data pixel for trees of $5 \mathrm{~m}$ height or taller. The tree canopy cover threshold is determined by practical ability to identify and map forest areas using Landsat data within boreal and temperate forests. Forest cover within European Russia is generally easily defined and mapped as most of the natural or managed forests have high canopy densities. All events resulting in forest stand replacement at the Landsat pixel scale within the analyzed time interval were considered as gross forest cover loss. Both analyzed forest cover change products include expert-driven characterization of the main drivers of forest cover loss (mechanical clearing, forest fires, and others). While expert-driven analysis is prone to classification errors, we anticipate that misclassification errors to be rare due to the relative simplicity and clarity of forest structure and stand-level forest dynamics processes within the boreal and hemiboreal regions of European Russia [2].

The objective of our study was to analyze forest cover change dynamics within European Russia and to highlight current forest management and conservation issues within the region through the comparison of the 1990-2000 and 2000-2005 forest cover change products. While our aim is to analyze existing satellite-derived forest cover change datasets, only a brief description of the mapping methodology is provided.

\section{Data and Methods}

2.1. Forest Cover Change Mapping 1990-2000. Landsat 5 TM and Landsat 7 ETM+ imagery freely available at the time of analysis through the Global Land Cover Facility (http://glcf.umiacs.umd.edu) were used as the source data for the 1990-2000 change detection. The GLCF images were appended with a set of ETM+ images purchased by Greenpeace for areas with frequent cloud cover. The image dates vary from 1985 to 1995 year (median year 1988) for TM images, and from 1999 to 2003 year (median year 2001) for ETM+ images. The observation density was low, with a single cloud-free acquisition available for each time interval for most of the region. The image preprocessing included image reprojection, image coregistration (for selected nonorthocorrected images), manual cloud masking, and mosaicing on a per scene basis. Two sets of mosaic were created-one using TM data for circa year 1990 and another using ETM+ data for circa year 2000. No radiometric normalization was performed requiring independent change detection analysis for every image pair. 
To select areas of forest cover loss, a simple threshold of Landsat band 5 (SWIR) difference between circa 1990 and circa 2000 images was chosen manually after examining each image pair. The threshold was selected in a way to include all forest cover loss areas. Selected areas, however, also included landscapes affected by other change dynamics (cropland areas due to differences in rotation stage, wetlands with water table level fluctuations, etc.). To exclude year 1990 nonforest areas from the change results, an unsupervised classification, ISODATA clustering [16], into 100 classes was performed for the TM data within the change mask. Forest classes were manually labeled by experts and used to produce the final forest cover loss map. To remove remaining noise in the change map, all change polygons with an area of less than 1 hectare were excluded from further analysis. The forest cover loss factors (fire, logging, and others) were manually assigned by experts for all change polygons. The burned areas were identified on reference imagery by shape and distinct spectral signatures of ash on the ground. Logging was identified by logging roads and characteristic shape patterns of cleared patches. Areas of agriculture clearing (a rare event for Russian European North), builtup areas expansion, and forest clearings for transportation infrastructure were mapped together with the "logging" class (Figure 1). Scattered disturbances, such as wind and snow damage, tree mortality caused by insect outbreaks, and disturbances of indeterminate origin were left as an "other" forest cover loss class. The final product was evaluated and manually corrected by regional experts; however, no independent validation of the product has been performed.

2.2. Forest Cover and Change Mapping 2000-2005. To map forest cover and change for the 2000-2005 interval, an exhaustive mining of the freely available USGS Landsat ETM+ data archive was performed, and all growing season images from 1999 to 2007 with cloud cover limited to 50\% were selected and used for analysis. As the vast majority of Landsat data were processed by USGS to the L1T (terraincorrected) standard, no further geocorrections were implemented. To facilitate image compositing, all Landsat data were reprojected to a standard 60-meter pixel grid, followed by radiometric normalization and image quality assessment to mask cloud/shadow contaminated observations. The simple relative radiometric normalization technique using a dark object subtraction (DOS) method [17] was employed using pure coniferous forest stands mapped for the entire region using MODIS data as a dark target. From the resulting set of normalized Landsat imagery, two image composites were created, one for circa year 2000 and another for circa year 2005 [15]. For each composite (2000 and 2005) more than $95 \%$ of the area was compiled from images acquired within \pm 1 year of the target composite year, with the rest compiled from images acquired within \pm 2 years of the target composite year.

The circa year 2000 and 2005 composites were used as source data for forest cover mapping for year 2000 and forest cover change detection from 2000 to 2005 using a bagged supervised classification tree algorithm [18]. To build the classification tree models, extensive "forest/nonforest" and "forest change/no change" training sets were manually created via visual interpretation of the composite images. First, the forest cover for circa year 2000 was mapped. Gross forest cover loss from 2000 to 2005 was mapped within the resulting year 2000 forest mask. Resulting forest cover and forest cover loss products were validated using available official regional forestry statistics and a set of independently derived forest and forest cover loss maps for a set of stratified sample blocks. The validation results showed sufficient quality of regional-scale forest cover and change mapping, with overall accuracies of $89 \%$ for forest cover mapping and 98\% for forest cover loss mapping results [15]. Assigning forest cover loss factors (fire, logging, and other) was performed using circa 2005 image photointerpretation following the same approach as that of the 1990-2000 time interval.

Areas where forest recovery was detected within the 5 -year period have been considered as gross forest cover gain. To map forest cover gain, training data were manually selected and used to create a bagged classification tree model. Forest cover gain areas were mapped within areas classified as nonforest in year 2000. The absence of reference data on forest regeneration did not allow us to validate the forest cover gain map.

2.3. Comparison Forest Cover Loss Results for 1990-2000 and 2000-2005. The joint area of 1990-2000 and 20002005 analysis covers 97\% of the Russian European North region with an exception of the Eastern part of the Ural Mountains in Komi and Perm regions, and the southern parts of Moscow, Nizhny Novgorod and Chuvash beyond 55 Northern Latitude (Figure 2). To provide a result comparison and to create a multitemporal map of forest cover loss, both products were reprojected to the same pixel grid (Figure 3). Because of different spatial resolutions of source datasets (30 m per pixel for 1990-2000 product and $60 \mathrm{~m}$ for 2000 2005 product), the coarser resolution of $60 \mathrm{~m}$ was selected for product aggregation. The 30-meter change map was averaged to a 60-meter resolution and then categorized into "change"/"no change" classes using a 50\% threshold of the forest cover loss class area fraction per pixel. The disturbance timing was also corrected as a significant portion of the 1990-2000 product was created using 2001-2003 Landsat observations while the 2000-2005 product mapped disturbances happened strictly after year 2000. For all disturbance in the aggregated multi-temporal map, the latest disturbance date was chosen (e.g., if area was mapped as forest cover loss for both 1990-2000 and 2000-2005 interval, the change event was attributed to the 2000-2005 interval only).

\section{Results}

3.1. Forest Cover for Year 2000. The forest cover for the Russian European North was mapped only for circa year 2000 


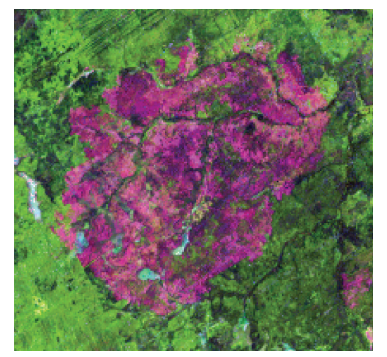

(a)

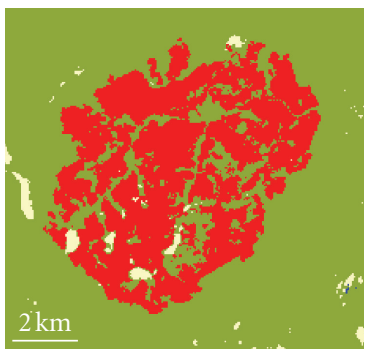

(b)

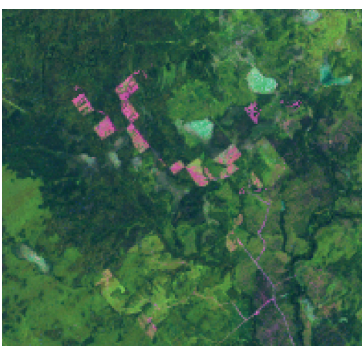

(c)

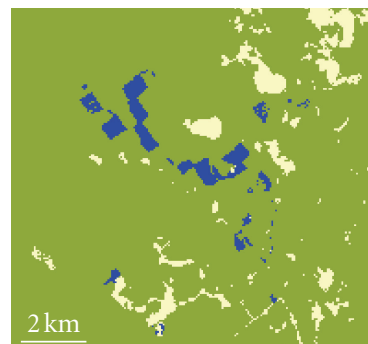

(d)

Figure 1: Example of burned area (a, b) and logging (c, d) expert-based identification. (a), (c) Landsat circa 2005 image mosaic. (b), (d) Forest cover and change 2000-2005 monitoring results (yellow: nonforest, green: forest, red: burned areas, blue: logging).

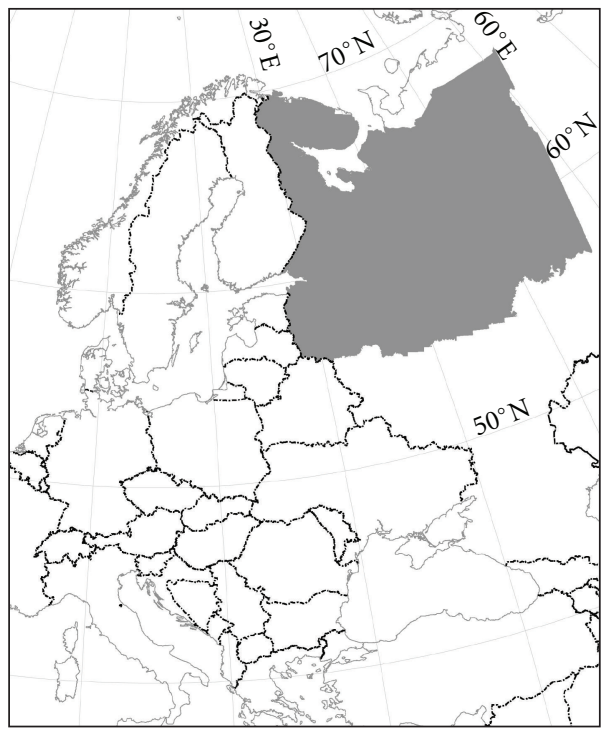

(a)

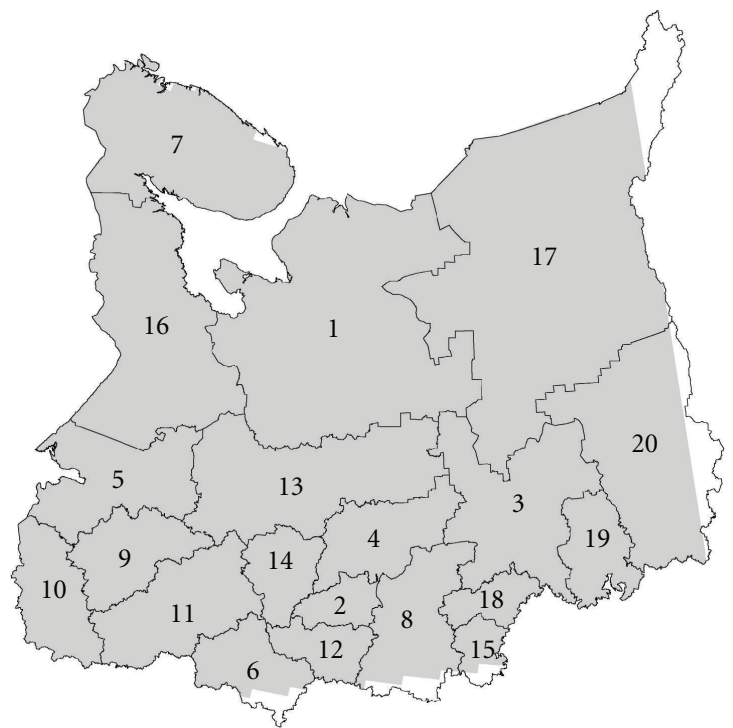

(b)

Figure 2: (a) Analyzed area of the Russian European North (selected in gray). (b) Administrative regions within area of analysis: (1) Arkhangelsk, (2) Ivanovo, (3) Kirov, (4) Kostroma, (5) Leningrad, (6) Moscow, (7) Murmansk, (8) Nizhny Novgorod, (9) Novgorod, (10) Pskov, (11) Tver, (12) Vladimir, (13) Vologda, and (14) Yaroslavl Oblast; (15) Chuvash, (16) Karelia, (17) Komi, (18) Mari-El, and (19) Udmurt Republic, and (20) Perm Kray.

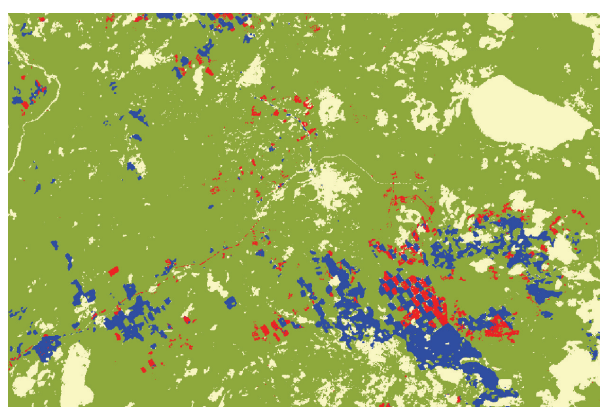

(a)

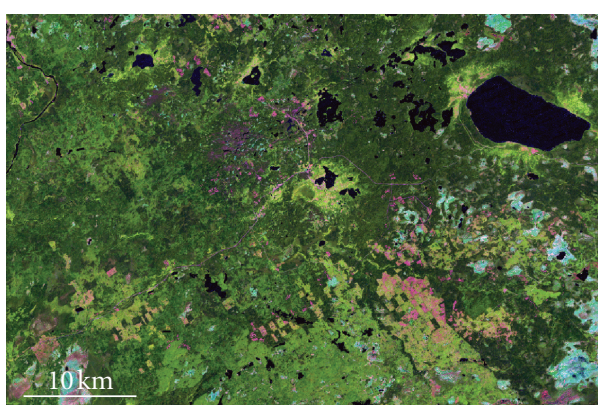

(b)

FIGURE 3: Integrated forest cover monitoring results for the 1990-2005 time interval. (a) Forest cover and change map (yellow: nonforest, green: forest for year 2000, blue: forest cover loss 1990-2000, red: forest cover loss 2000-2005). (b): Landsat circa 2005 image mosaic. 
and was estimated to be 127.3 million ha. The last available Russian Forest Service data for year 2003 [5] estimated area covered by forest (excluding temporally unstocked lands) for the analyzed administrative regions to be 129.6 million ha. A comparison of official and Landsat-based forest cover areas estimates per region showed high correlation $\left(R^{2}\right.$ of 0.996 , Figure 4). Forest cover was underestimated for Perm Kray (Figure 4) where 14\% of the region was outside of the area of analysis (Figure 2).

3.2. Gross Forest Cover Loss 1990 to 2005. Gross forest cover loss was mapped separately for two time intervals and estimated as 5.3 million ha for 1990-2000 and 2.0 million ha for 2000-2005. The mean annual gross forest cover loss was 528 thousand ha/year for 1990-2000 comparing to 402 thousand ha/year for 2000-2005. While the total gross forest cover loss intensity decreased between the two intervals, regional scale forest cover loss estimates illustrate heterogeneity in forest cover dynamics within the Russian European North. For the 1990-2000 interval, the three largest forest regionsKomi, Arkhangelsk, and Perm-were responsible for more than $50 \%$ of total gross forest cover loss. In contrast, for the 2000-2005 interval, almost 50\% of total loss occurred within Arkhangelsk, Komi, Karelia, and Leningrad, illustrating a shift of change intensity toward the Western part of the territory.

Whereas the total annual gross forest cover loss area decreased within the Russian European North, the annual loss increased by 17 thousand ha/year in Leningrad, by 10 thousand ha/year in Moscow, and by 9 thousandha/year in Pskov and Tver. The highest relative increases in forest cover loss were detected for Moscow (more than 3 times), Pskov (twice), Vladimir and Ivanovo (1.5 times) between the two study intervals. On the other hand, gross forest cover loss decreased within Northern and Eastern part of the region. The highest decreases were detected in Komi (by 74 thousand ha/year), Arkhangelsk (by 38 thousand ha/year), and Perm (by 36 thousand ha/year). Relative decrease was the highest for the Eastern part of the Russian European North, where annual gross forest cover loss decreased by more than a factor of two.

3.2.1. Changes in Logging Intensity. Clear-cut logging (including timber harvesting and forest clearing due to settlement expansion or infrastructure construction) is thought to be the single most important factor of gross forest cover loss within the Russian European North, contributing $89 \%$ of total forest cover loss from 1990 to 2005 . The annual logging area, however, decreased between the 19902000 and 2000-2005 time intervals by 33\% (from 488 to 327 thousand ha/year). At the regional scale, the changes in logging intensity are almost similar to the gross forest cover loss trends (Figure 5(a); Table 1). The highest annual logging increase (by 13 thousand ha/year) was observed in Leningrad. Annual logging area increased by a factor of three in Moscow, and significantly increased in other Central and Western regions. Logging area decreased within the Northern and Eastern regions (Table 1), specifically within Murmansk,

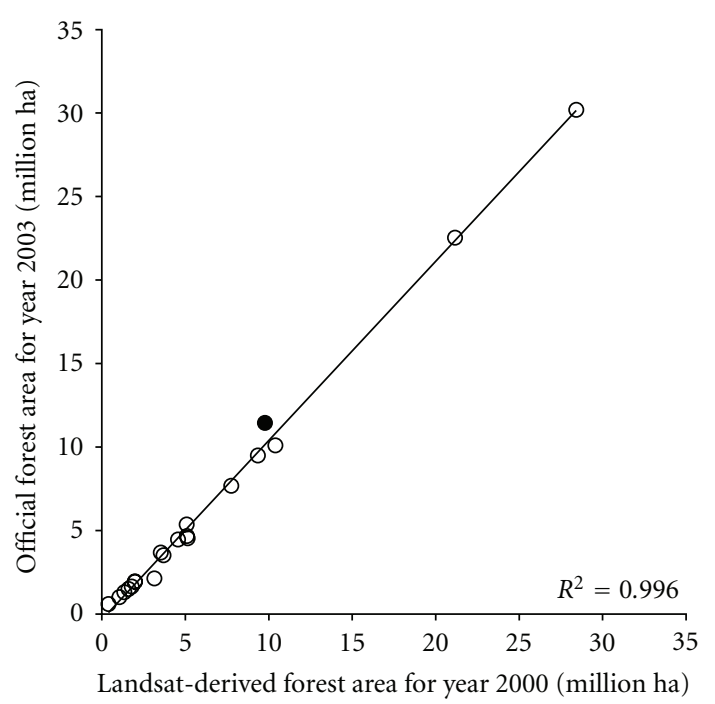

FIGURE 4: Comparison of Landsat-derived forest cover area for circa year 2000 per administrative region with official forest cover area for year 2003 [5]. Selected (black) data point represents Perm Kray where underestimation of Landsat-based forest cover area is due to limited area of analysis which does not include the entire region.

Komi, and Perm regions where it decreased by a factor of three. However, in Karelia logging intensity remained nearly constant (4\% reduction).

The fraction of industrial clearing within total gross forest loss also changed between the two time intervals. For the 1990-2000 decade, almost 92\% of all change was attributed to logging, with the remaining $6 \%$ attributed to fire, and the rest to other or indeterminate forest cover loss factors. In contrast, for the 2000-2005 interval, logging comprised only $81 \%$ of forest cover loss area, with $18 \%$ attributed to fire, and $1 \%$ to the "other" forest cover loss class.

3.2.2. Changes in Fire Dynamic. Forest fires play a comparatively small role in gross forest cover loss in European Russia with an exception of some catastrophic fire years, for example, 2010. Our current analyses illustrate that burned areas comprise $9.5 \%$ of total forest cover loss over 15 years. However, the annual forest burned area changed dramatically during the 1990-2005 study period. The average annual burned forest area more than doubled between the 1990-2000 and 2000-2005 time intervals (from 33 thousand ha/year to 73 thousand ha/year), and the distribution of fire affected area changed significantly (Figure 5(b); Table 1). The annual burned area increased in all regions except Vologda, Chuvash and Udmurt. The highest annual burned area increase (by 3-5 thousand ha/year) was observed in the Central part of the region. Annual burned area also increased in Arkhangelsk and Komi; however, the relative increase in Komi was comparatively small (24\%).

Comparing the two time intervals, the distribution of burned area by region shifted from the Northern to the Central part of the territory. For the 1990-2000 interval, 85\% of all burned area was allocated within the Northern part 
TABLE 1: Forest cover for year 2000 and annual gross forest cover loss attributed to logging (and other forms of anthropogenically-induced clearing) and wildfires for 1990-2000 and 2000-2005 time intervals per administrative region.

\begin{tabular}{|c|c|c|c|c|c|}
\hline \multirow[t]{2}{*}{ Region } & \multirow[t]{2}{*}{$\begin{array}{l}\text { Forest cover for } \\
\text { year } 2000 \text {, } \\
\text { thousand ha }\end{array}$} & \multicolumn{2}{|c|}{$\begin{array}{l}\text { Annual gross forest } \\
\text { cover loss attributed to } \\
\text { logging, thousand ha }\end{array}$} & \multicolumn{2}{|c|}{$\begin{array}{l}\text { Annual gross forest cover } \\
\text { loss attributed to } \\
\text { wildfires, thousand ha }\end{array}$} \\
\hline & & $1990-2000$ & $2000-2005$ & $1990-2000$ & 2000-2005 \\
\hline (1) Arkhangelsk Oblast & 21162.3 & 102.0 & 58.8 & 2.1 & 6.5 \\
\hline (2) Ivanovo Oblast & 1058.3 & 1.8 & 3.8 & 0.0 & 0.8 \\
\hline (3) Kirov Oblast & 7761.3 & 45.0 & 28.4 & 0.4 & 1.1 \\
\hline (4) Kostroma Oblast & 4561.6 & 18.3 & 15.9 & 0.0 & 0.4 \\
\hline (5) Leningrad Oblast & 5099.7 & 16.5 & 29.7 & 1.7 & 5.9 \\
\hline (6) Moscow Oblast & 1984.6 & 3.0 & 9.4 & 0.0 & 3.4 \\
\hline (7) Murmansk Oblast & 5088.4 & 7.8 & 2.2 & 2.2 & 3.9 \\
\hline $\begin{array}{l}\text { (8) Nizhny Novgorod } \\
\text { Oblast }\end{array}$ & 3537.1 & 9.9 & 7.4 & 0.3 & 2.8 \\
\hline (9) Novgorod Oblast & 3695.8 & 8.6 & 13.0 & 0.4 & 1.8 \\
\hline (10) Pskov Oblast & 3146.0 & 4.4 & 8.2 & 0.0 & 5.3 \\
\hline (11) Tver Oblast & 5148.0 & 10.4 & 15.8 & 0.3 & 4.2 \\
\hline (12) Vladimir Oblast & 1598.3 & 4.5 & 7.2 & 0.1 & 4.5 \\
\hline (13) Vologda Oblast & 10394.5 & 44.9 & 33.5 & 0.8 & 0.6 \\
\hline (14) Yaroslavl Oblast & 1791.5 & 2.8 & 3.4 & 0.0 & 0.7 \\
\hline (15) Chuvash Republic & 397.2 & 1.5 & 0.6 & 0.0 & 0.0 \\
\hline (16) Karelia Republic & 9352.3 & 36.1 & 34.4 & 0.7 & 1.3 \\
\hline (17) Komi Republic & 28415.9 & 104.2 & 31.1 & 21.4 & 26.7 \\
\hline (18) Mari-El Republic & 1343.5 & 3.3 & 2.4 & 0.0 & 0.3 \\
\hline (19) Udmurt Republic & 1978.5 & 8.8 & 4.2 & 0.0 & 0.0 \\
\hline (20) Perm Kray & 9765.3 & 54.0 & 17.6 & 2.3 & 2.8 \\
\hline
\end{tabular}

of the region (Arkhangelsk, Murmansk, Komi, and Perm). However, for the 2000-2005 time interval, these regions accounted for only 55\% of the total burned area, while Leningrad, Moscow, Pskov, Vladimir, and Tver accounted for $32 \%$.

3.3. Gross Forest Cover Gain and Net Forest Cover Area Change 2000 to 2005. Gross forest cover gain was mapped only for the 2000-2005 time interval and was estimated to be 1.9 million ha (or 390 thousand ha/year). The area of gross forest cover gain for 2000-2005 was highest for Arkhangelsk, Komi, and Perm. A significant fraction of gross forest cover gain from 2000-2005 (39\%) was colocated with areas that experienced forest cover loss during the previous decade (1990-2000). For the year 2000, 41\% of clearings from 19902000 were already reforested by year 2000 , with an additional 14\% reforested between 2000 and 2005; the remaining 45\% was still considered nonforest in 2005.

Gross forest cover gain is only slightly lower compared to gross forest cover loss for the 5-year interval, which resulted in a small net reduction of forest cover by 62 thousand ha (representing $0.04 \%$ of year 2000 forest cover). The net forest cover change for 2000-2005 was negative for 11 out of 20 regions, with the highest decrease observed for Leningrad, Karelia, Moscow, and Vladimir $(-118,-117,-56$, and -30 thousand ha, resp.). Moscow region had the highest net forest cover loss relative to the region's forest cover for year $2000(-2.8 \%)$, followed by Leningrad $(-2.3 \%)$ and Vladimir $(-1.9 \%$, Figure $5(\mathrm{c}))$. The highest net forest cover gain was observed in Perm and Kirov (+166 and +116 thousand ha, resp.). These regions also have the highest relative net forest cover gain $(+1.7 \%$ and $+1.5 \%$ of year 2000 forest cover, resp.).

\section{Discussion}

4.1. Industrial Forest Use and Forest Clearing. The observed gross forest cover loss area and, specifically, logging intensity decrease between the 1990-2000 and 2000-2005 time intervals was confirmed with official forest harvesting statistics. The logging intensity within European Russia grew rapidly after World War II, peaking in the late 1960s with a gradual decrease from the early 1970s through the 1990s [19]. After the breakdown of the Soviet planned economy in the early 1990s, logging intensity dropped significantly. The average annual roundwood production decreased by $60 \%$ for the 2000-2005 interval compared to year 1990 for selected regions of European Russia [1]. In the late 1990s and early 2000s, high demand for timber from foreign and domestic industry stimulated a slight increase in logging intensity, with roundwood production increasing by $8 \%$ between 2000 and 2005. 


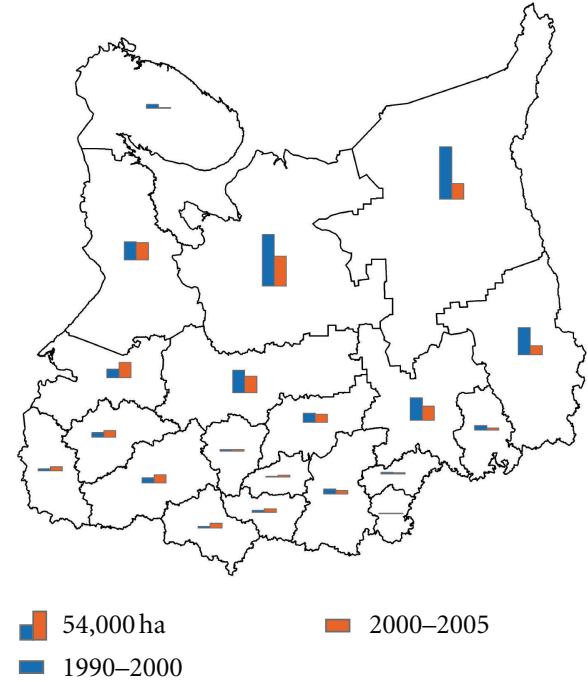

(a)

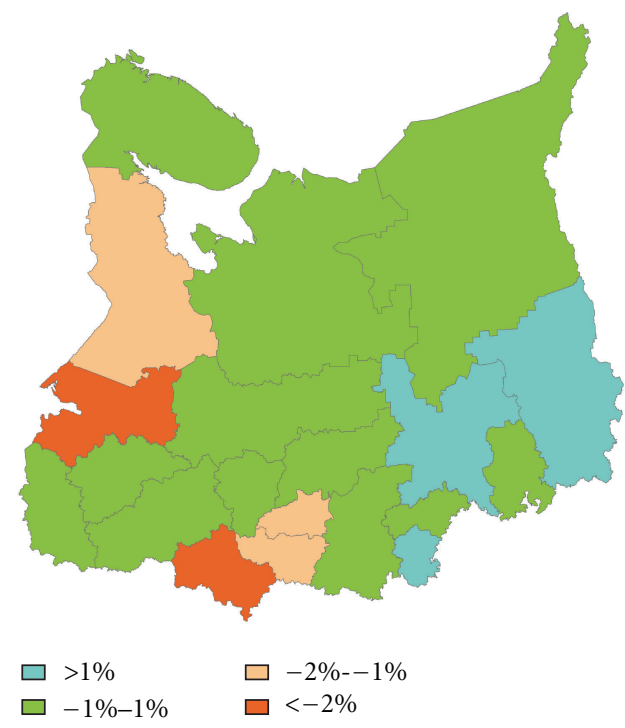

(c)

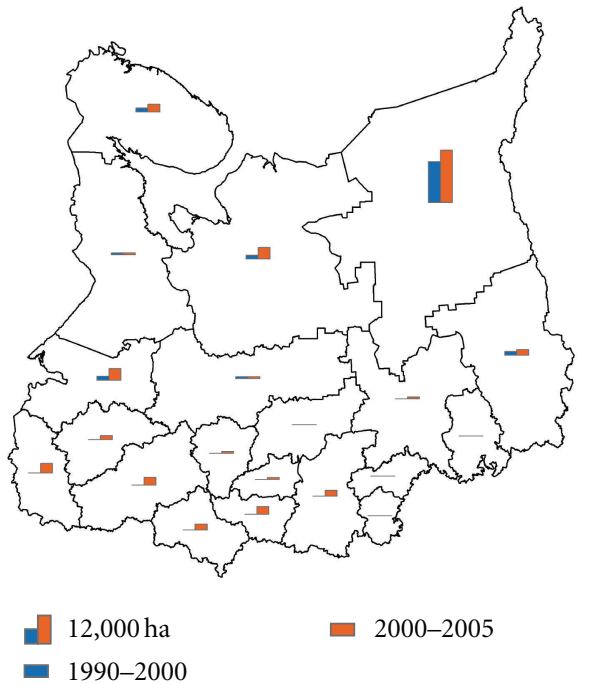

(b)

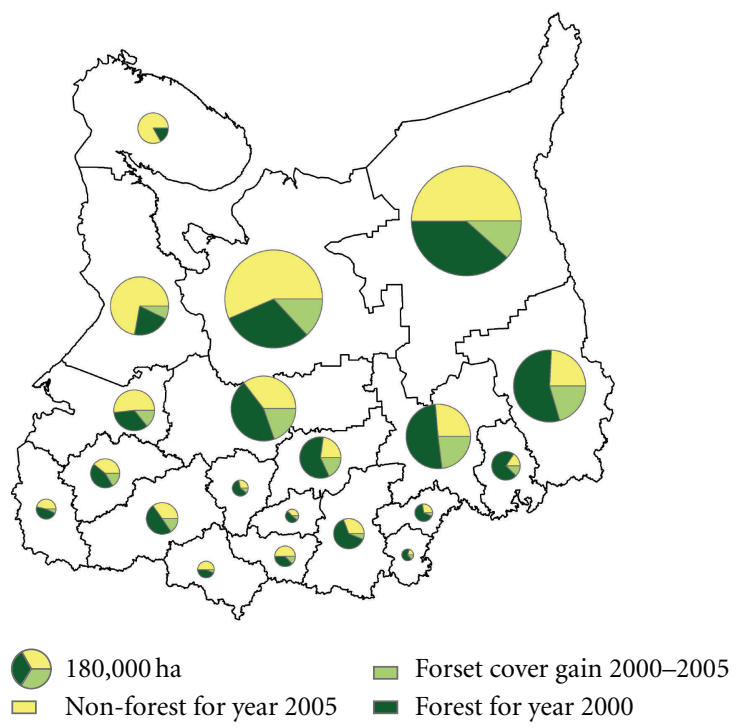

(d)

Figure 5: Regional forest cover change statistics. (a) Annual gross forest cover loss attributed to logging, 1990-2000 and 2000-2005. (b) Annual gross forest cover loss attributed to wildfires, 1990-2000 and 2000-2005. (c) Net forest cover change 2000-2005, as percent of forest cover for year 2000. (d) Proportion of forest 2000, nonforest 2005 and forest cover gain 2000-2005 classes within areas cleared from 1990 to 2000 .

The official roundwood production data at the regional level agreed with our logging area estimates. According to official data [1], the top forest production region for both 1990 and 2005 was Arkhangelsk which produced more than $16 \%$ of total roundwood harvested in the region. Two other large forest regions, Komi and Perm, held the second and third rank by roundwood production for year 1990. For the year 2005, however, they were replaced by Karelia and Vologda. While the roundwood production decreased in every region in European Russia between 1990 and 2005, the rate of change was different. The lowest roundwood production decrease (below 30\%) was observed in Pskov and Leningrad. Other regions that retained more than $50 \%$ of their 1990 production in year 2005 were Karelia, Tver, Vologda, and Ivanovo. The highest roundwood production decrease (by 90\%) was registered for Murmansk. The forest use intensity, measured as roundwood production per area unit, also changed. For 1990, the regions with the most intensive timber extraction were Kostroma, Kirov, and Perm. For 2005, the three regions with the highest rates of timber extraction were Kostroma, Leningrad, and Vologda.

We suggest that the most important factor responsible for changes in industrial forest clearing within the Russian European North was the roundwood consumption dynamic after the breakdown of the Soviet Union in 1992. The forest 
resources of the region have traditionally supplied both the domestic forest industry and timber processing industry in Europe, particularly for the Nordic countries. Finland has traditionally been one of the key importers of roundwood harvested in European Russian forests [20]. After the year 1992, the roundwood production decreased considerably, primarily following reduction in domestic timber demand. However, roundwood export continued to rise over the study period, causing a noticeable shift in logging intensity towards more densely populated and accessible areas, and especially to the regions close to the Russian-Finland border. Our results revealed intensive gross forest cover loss close to the Russian-Finland frontier (Leningrad and Karelia). If the intensive forest cover loss within these regions is not compensated by forest restoration, this could lead to forest resource depletion and consequent environmental and social problems. On the other hand, logging intensity was considerably reduced in the remote Eastern regions of Komi and Perm.

One of the highest forest cover loss rate increases was detected within the most populated regions of European Russia: Leningrad and Moscow. These regions, including the cities of St. Petersburg and Moscow, comprise almost $27 \%$ of the total population of the analyzed region [1]. While gross forest cover loss in Leningrad is believed to be mostly connected with intensive timber harvesting, the forest cover loss in Moscow was a consequence of several factors, including logging and built-up area expansion. For example, the expansion of settlements and industrial facilities around Moscow city caused the conversion of about 58 thousand ha of former forest and agriculture lands from 1998 to 2008 [21]. Illegal logging and illegal site development connected to failures in forest governance and/or a lack of law enforcement [22] worsened the situation. The remaining forests around large industrial cities provide ecological services (e.g., water and air purification, natural species refuge, recreation) important to urban populations. Our results raise concerns about the fate of the remaining forests in the most populated regions of European Russia.

Another threat to forest ecosystems within the Russian European North is the large-scale industrial logging activity along the boundary of undeveloped forest areas primarily located within the North-Eastern part of the region. While Arkhangelsk and Komi share the largest part of remaining intact forest landscapes of the Europe [23], they also represent the largest gross forest cover loss area within the region. The remaining intact landscapes tend to be remote, unproductive, and poorly stocked in comparison to what is usually considered minimum levels for sustainable forestry [24]. However, the depletion of available timber resources within more accessible and productive forests of European Russia has led to intensive exploitation of previously undeveloped areas. While the visual analysis of 1990-2005 gross forest cover loss dataset highlighted heretofore intact forest areas affected by rapid expansion of industrial logging, no detailed analysis of intact forest area change was performed in the current research.

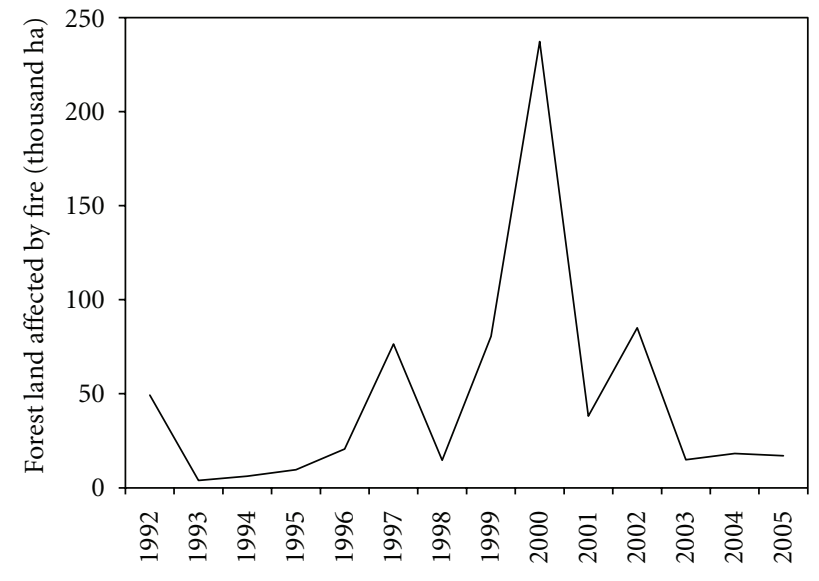

Figure 6: Burned forest area for selected 20 administrative regions [30].

4.2. Wildfires. European Russia forest fire regimes are well studied; however, area burned estimates vary depending on data sources. In general, the majority of satellite-based annual area burned estimates are an average 5 to 10 times higher than official Russian data $[7,25]$. There are several issues responsible for such uncertainty, including predominance of surface fires within pine forests of Northern Eurasia [26]. While surface fires affected vast areas of boreal forests, their effect on forest cover, direct carbon emissions, albedo change, and postfire successional trajectories is different from stand-replacement fires $[27,28]$. Our method of forest burned area assessment differs from most official and remote-sensing based analyses as it was made only within forests with high (above 25\%) tree canopy density and consequently quantified only those forested areas affected by stand-replacement fires.

Our results confirmed previous MODIS-based forest cover change analysis that estimated low forest cover loss due to wildfires within the European part of Russia [29]. According to official data [1], the largest annual forest area affected by fire since 1992 was detected during the extreme fire seasons of 1997, 1999, 2000, and 2002 (Figure 6). These fire events affected different parts of the Russian European North: North-Western part (Arkhangelsk, Murmansk) in 1997; Western regions (Karelia, Tver, Yaroslavl, Novgorod, Leningrad, and Vologda) in 1999; North-Eastern part (Arkhangelsk, Komi, and Perm) in 2000; and Central part (Vladimir, Ivanovo, Moscow, Kostroma, Tver, Yaroslavl, Leningrad, Novgorod, Pskov, Nizhniy Novgorod, and Mary El) in 2002.

Komi Republic is the single largest contributor of burned forest area within the region, comprising almost $50 \%$ of the total burned forests from 1990 to 2005. The largest fire event over the analyzed time interval happened in 2000, when large-scale uncontrolled fires spread over the northern part of the Republic. The expansion of fires during the last year of the 1990-2000 assessment, and the starting point of the 2000-2005 analysis made it complicated to correctly map the year of fire event. While most of the fires were 
correctly mapped as a part of 1990-2000 interval dataset, the difference in model sensitivity to burned area detection caused some portion of burned area to be mapped as change during 2000-2005 time interval. Another factor contributing to this uncertainty is the larger amount of cloud-free Landsat imagery available for the year 2001 compared to 2000, which could cause a one year lag for change detection. These uncertainties could be responsible for the overestimation of change detected during the 2000-2005 interval for Komi.

The 2000-2005 shift in burned area allocation from the northern to the central part of the region is connected with the extreme fire season of 2002, when severe drought conditions and human-induced fires led to extensive forest cover loss within the central regions of European Russia. Most of the forest fires were initiated in and spread from large areas of peat bogs and pine forests on peat soils in Moscow, Vladimir, Tver, Nizhny Novgorod, and Pskov regions. Large parts of these wetlands had been drained and used for peat extraction during the 20th century. During the late summer of 2002, dry weather conditions coupled with the extensive use of fire for managing grasslands near settlements on peat soils caused fire to spread to the surrounding forests [31]. According to official data, the forest burned area in Moscow region for 2002 was about 10 times higher compared to the mean annual burned area from 1992 to 2005 [30].

4.3. Reforestation and Afforestation. We posit that the major factors of gross forest cover gain are forest regrowth on clear-cuts and burned areas, followed by tree expansion on abandoned agriculture lands in the Southern part of the Russian European North. The clear-cut and burned forest areas in Russia are often left for natural forest regeneration, however, in some cases, forest restoration could be supported by tree planting or seeding. The official statistics document annual forest restoration areas for the 2000-2005 interval [1]. However, these data did not reflect the actual forest regrowth, which makes the forest cover gain figures incompatible with our findings.

Of the total gross forest cover gain detected for the 2000-2005 interval, 39\% happened within areas cleared since 1990. These areas represent natural reforestation or successful forest planting. In general, the fraction of 19902000 forest clearings reforested by year 2005 (Figure 5(d)) constitutes a forest recovery rate. The highest forest recovery rates were detected for the Southern part of the region, with most favorable climatic conditions for fast tree growth; forest regeneration within the Northern part of the territory was slow. Apart from this general tendency, several regions have low gross forest cover gain rates, including Leningrad, Moscow, and Vladimir. We suppose that forest cover clearing within these regions could be a consequence of urban growth and infrastructure development, dynamics where forest cover has been permanently converted into nonforest land-cover types.

The remaining $61 \%$ of forest cover gain was found on logged or burned areas cleared before 1990, or as tree encroaching on abandoned agricultural lands. Agriculture land abandonment and consequent forest expansion was widespread during the transition from planned to marketoriented economies in the former Soviet Republics [32, 33]. The land abandonment of 1992-1997, during the first years after Soviet Union collapse, was the most intensive leavening large land parcels unmanaged and subject to natural forest restoration. The cropland area for the selected 20 regions of year 2005 was only $60 \%$ of the total cropland area managed in 1990, illustrating this wide-scale abandonment [1]. Almost half of the total abandoned land area was located within four regions: Kirov, Tver, Nizhny Novgorod, and Perm. The highest rates of land abandonment, according to official statistics, were observed in the Western part of the region (Novgorod, Pskov, Tver), where management ended for more than half of the former agriculture lands. These regions represent the intensive degradation of the Soviet agriculture system, where limited government subsidies and low crop productivity led to large-scale land abandonment. Forest restoration on former agriculture lands is not included in the official forest cover area statistics. The afforestation of former agriculture lands could have major consequences to regional carbon budgets and should be included in European forest cover monitoring [32].

Forest cover gain mapping within the analyzed 5-year interval in boreal and hemiboreal regions is challenging due to the slow regeneration of forest cover. While dense young forests could regrow within a 5-year interval in the southern part of European Russia, northern boreal stand regeneration requires more time. Moreover, the transition from young open tree stands classified as nonforest for year 2000 to closed stands in year 2005 within northern taiga could not be correctly visually interpreted using medium resolution Landsat data. The forest cover gain mapping approach is shown here only as a prototype that would be possible over longer (e.g., 10 years) intervals, given adequate forest cover change training data.

\section{Conclusion}

Independent satellite-based monitoring of boreal forests is an important tool for providing transparent information on forest cover change. Government officials, land managers, researchers, conservationists, and civil society groups can use such information to make better-informed decisions regarding the management of boreal ecosystems. Our results depicting forest cover change for the vast forest region of Russian European North over 15 years illustrate that such analysis could be performed using freely available Landsat data and an automated image processing approach. Continuation of such analyses, its extension to the rest of the country, and publication of mapping results would be a significant step toward establishing a transparent system for independent national scale forest cover monitoring. The authors envision that the analysis will be expanded to cover the entire pan-boreal biome as well as the 2000-2010 interval.

Expert-driven forest cover monitoring using historic Landsat data is a well-developed approach and its accuracy for forest cover and change detection ranges between $75 \%$ 
and $91 \%[34,35]$. This high accuracy level has been confirmed through our year 2000 forest cover map (overall accuracy 89\%) and 2000-2005 forest cover loss monitoring product (overall accuracy 98\%) [15]. The 1990-2000 forest cover monitoring data used for our analysis have been crosschecked by different regional experts, and are believed to be of similar accuracy. Two main factors precluded validation of historical forest cover change trend analysis within European Russia. First, the fine-scale forest assessment maps from the end of the Soviet era and from the decade immediately after the USSR breakdown are not publicly available. Second, the commercial high spatial resolution satellite data often used for validation of Landsat-derived area estimates are not available before year 2000. Analyzed forest cover change datasets, such as the 1990-2000 product, even they were not rigorously validated, are the only publicly available spatially consistent region-wide depiction of forest cover change making them an invaluable data source for studying forest dynamics. A possible source of independently collected validation data is the UNFAO Remote Sensing Survey, a sample-based assessment of global forest land-use change 1990-2005, based on Landsat imagery [36]. These sample data, when it will be publicly available, could be used for validation of our wall-to-wall product.

The analysis of gross forest cover loss during 1990-2005 highlighted several trends in forest cover change since the breakdown of the planned economy. Our results showed that while the total region-wide logging area decreased, logging and other forms of anthropogenic clearings increased within the Central and Western parts of the region. The most populated regions of European Russia (Leningrad and Moscow) featured the highest rate of forest cover loss. Forest cover depletion around large industrial cities should be highlighted as the single most important challenge facing current forest management in the European part of Russia. Our results also revealed intensive gross forest cover loss due to forest felling close to the Russian-Finland border (Leningrad and Karelia). The forest area affected by wildfire increased almost twice during the analyzed time interval. The burned area increase is a consequence of several factors, including distribution of extreme fire events, and, possibly, deterioration of the fire prevention service. The last factor has been once more confirmed during the extreme fire event of the year 2010. Our gross forest cover gain monitoring result suggested that tree cover encroaching on abandoned agriculture land is a wide-spread process over the region and should be quantified by more precise analysis. All such trends could be in full or partly confirmed by official forest and agriculture statistics. Our analysis supplemented official statistics by providing independently derived spatial data that could be used for assessing the ongoing trends and serve as a baseline for future forest cover monitoring.

Our study reflected only quantitative changes in forest cover, that is, the total forested area change. Other forest management effects, like anthropogenic landscape fragmentation and alteration of tree species composition were not analyzed. We suggest, however, that the presented approach for large-scale Landsat-based forest mapping and change analysis could be used to quantify most of these effects in further studies.

\section{References}

[1] ROSSTAT (Russian Federal State Statistics Service), Regions of Russia: Social and Economic Indicators, ROSSTAT, Moscow, Russia, 2008.

[2] V. N. Kalyakin, O. V. Smirnova, M. V. Bobrovskii, S. A. Turubanova, P. V. Potapov, and A. Y. Yaroshenko, "History of the Eastern European forest cover," in Forests of Eastern Europe, O. V. Smirnova, Ed., pp. 51-153, Nauka, Moscow, Russia, 2004.

[3] J. H. M. Thornley and M. G. R. Cannell, "Managing forests for wood yield and carbon storage: a theoretical study," Tree Physiology, vol. 20, no. 7, pp. 477-484, 2000.

[4] T. Kaipainen, J. Liski, A. Pussinen, and T. Karjalainen, "Managing carbon sinks by changing rotation length in european forests," Environmental Science and Policy, vol. 7, no. 3, pp. 205-219, 2004.

[5] VNIILM (All-Russia Research Institute of Forestry and Mechanization), "Forest Fund of Russia (State forest inventory data, status for January 1, 2003)," VNIILM, Moscow, Russia, 2003.

[6] S. Nilsson, A. Shvidenko, V. Stolbovoi, M. Gluck, M. Jonas, and M. Obersteiner, "Full carbon account for Russia," Interim Report, IIASA, Laxenburg, Austria, 2000.

[7] A. J. Soja, A. I. Sukhinin, D. R. Cahoon, H. H. Shugart, and P. W. Stackhouse, "Avhrr-derived fire frequency, distribution and area burned in siberia," International Journal of Remote Sensing, vol. 25, no. 10, pp. 1939-1960, 2004.

[8] M. Karpachevskiy, "Availability of forest information in Russia: current status and the outlook," Earth from Space, vol. 11, pp. 36-44, 2011.

[9] A. Y. Yaroshenko, A. F. Komarova, and M. L. Kreindlin, The second anniversary of the new Forest Code of Russian Federation, Greenpeace Russia, Moscow, Russia, 2009.

[10] M. Wulder, "Optical remote-sensing techniques for the assessment of forest inventory and biophysical parameters," Progress in Physical Geography, vol. 22, no. 4, pp. 449-476, 1998.

[11] A. Y. Yaroshenko, D. A. Dobrynin, A. V. Egorov et al., Central and Northern European Russia's Forests, Greenpeace Russia, Moscow, Russia, 2008.

[12] C. E. Woodcock, R. Allen, M. Anderson et al., "Free access to landsat imagery," Science, vol. 320, no. 5879, p. 1011, 2008.

[13] M. C. Hansen, D. P. Roy, E. Lindquist, B. Adusei, C. O. Justice, and A. Altstatt, "A method for integrating modis and landsat data for systematic monitoring of forest cover and change in the congo basin," Remote Sensing of Environment, vol. 112, no. 5, pp. 2495-2513, 2008.

[14] D. P. Roy, J. Ju, K. Kline et al., "Web-enabled landsat data (weld): landsat etm + composited mosaics of the conterminous united states," Remote Sensing of Environment, vol. 114, no. 1, pp. 35-49, 2010.

[15] P. Potapov, S. Turubanova, and M. C. Hansen, "Regionalscale boreal forest cover and change mapping using landsat data composites for european russia," Remote Sensing of Environment, vol. 115, no. 2, pp. 548-561, 2011.

[16] ERDAS, ERDAS Field Guide, ERDAS, Norcross, Ga, USA, 2010.

[17] P. S. Chavez, "An improved dark-object subtraction technique for atmospheric scattering correction of multispectral data," Remote Sensing of Environment, vol. 24, no. 3, pp. 459-479, 1988. 
[18] L. Breiman, "Bagging predictors," Machine Learning, vol. 24, no. 2, pp. 123-140, 1996.

[19] Russian Federal Forest Service, Forest Use in the Russian Federation during 1946-1992, Russian Federal Forest Service, Moscow, Russia, 1996.

[20] Yu. Gerasimov, S. Karvinen, and T. Leinonen, Atlas of the Forest Sector in Northwest Russia, METLA, Helsinki, Finland, 2009.

[21] M. L. Karpachevskiy, Y. E. Zenkevitch, D. A. Aksenov et al., Natural Environment of Moscow Region: Losses 1992-2008 and Current Threats, Biodiversity Conservation Center, Moscow, Russia, 2009.

[22] A. Morozov, Survey of Illegal Forest Felling Activities in Russia (forms and Methods of Illegal Cuttings, Greenpeace Russia, Moscow, Russia, 2000.

[23] P. Potapov, A. Yaroshenko, S. Turubanova et al., "Mapping the world's intact forest landscapes by remote sensing," Ecology and Society, vol. 13, no. 2, article no. 51, 2008.

[24] A. Y. Yaroshenko, P. V. Potapov, and S. A. Turubanova, The Last Intact Forest Landscapes of Northern European Russia, Greenpeace Russia, Moscow, Russia, 2001.

[25] J. G. Goldammer, A. Sukhinin, and I. Csiszar, "The current fire situation in the Russian Federation: implications for enhancing international and regional cooperation in the UN framework and the global programs on fire monitoring and assessment," International Forest Fire News, vol. 32, pp. 13-42, 2005.

[26] G. N. Korovin, "Analysis of the distribution of forest fires in Russia," in Fire in Ecosystems of Boreal Eurasia, J. G. Goldammer and V. V. Furyaev, Eds., pp. 112-128, Kluwer Academic Publishers, Dordrecht, Netherlands, 1996.

[27] M. J. Wooster and Y. H. Zhang, "Boreal forest fires burn less intensely in russia than in north america," Geophysical Research Letters, vol. 31, no. 20, 4 pages, 2004.

[28] S. J. Goetz, M. C. MacK, K. R. Gurney, J. T. Randerson, and R. A. Houghton, "Ecosystem responses to recent climate change and fire disturbance at northern high latitudes: observations and model results contrasting northern eurasia and north america," Environmental Research Letters, vol. 2, no. 4, Article ID 045031, 9 pages, 2007.

[29] P. Potapov, M. C. Hansen, S. V. Stehman, T. R. Loveland, and K. Pittman, "Combining modis and landsat imagery to estimate and map boreal forest cover loss," Remote Sensing of Environment, vol. 112, no. 9, pp. 3708-3719, 2008.

[30] ROSSTAT (Russian Federal State Statistics Service), "Central Statistics Database," Moscow, Russia, 2011, http://www.gks.ru/ free_doc/new_site/business/sx/les2_bd.htm.

[31] A. Grigoriev, "Forest and peat fires of year 2002," Forest Bulletin, vol. 21-22, pp. 1-4, 2003.

[32] T. Kuemmerle, O. Chaskovskyy, J. Knorn et al., "Forest cover change and illegal logging in the ukrainian carpathians in the transition period from 1988 to 2007," Remote Sensing of Environment, vol. 113, no. 6, pp. 1194-1207, 2009.

[33] G. Ioffe, T. Nefedova, and I. Zaslavsky, "From spatial continuity to fragmentation: the case of russian farming," Annals of the Association of American Geographers, vol. 94, no. 4, pp. 913-943, 2004.

[34] P. R. Coppin and M. E. Bauer, "Processing of multitemporal landsat tm imagery to optimize extraction of forest cover change features," IEEE Transactions on Geoscience and Remote Sensing, vol. 32, no. 4, pp. 918-927, 1994.

[35] T. Saksa, J. Uuttera, T. Kolström, M. Lehikoinen, A. Pekkarinen, and V. Sarvi, "Clear-cut detection in boreal forest aided by remote sensing," Scandinavian Journal of Forest Research, vol. 18 , no. 6, pp. 537-546, 2003.

[36] FAO, “The 2010 Global Forest Resources Assessment Remote Sensing Survey: an outline of the objectives, data, methods and approach," FAO FRA Paper 155, FAO, Rome, Italy, 2009. 

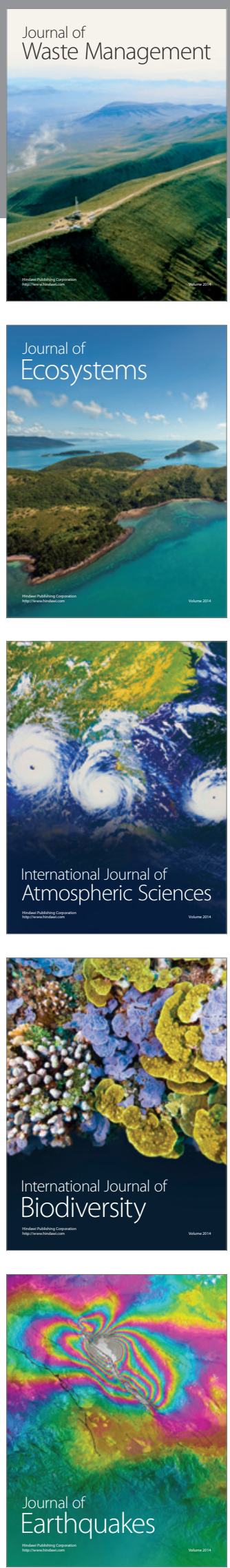
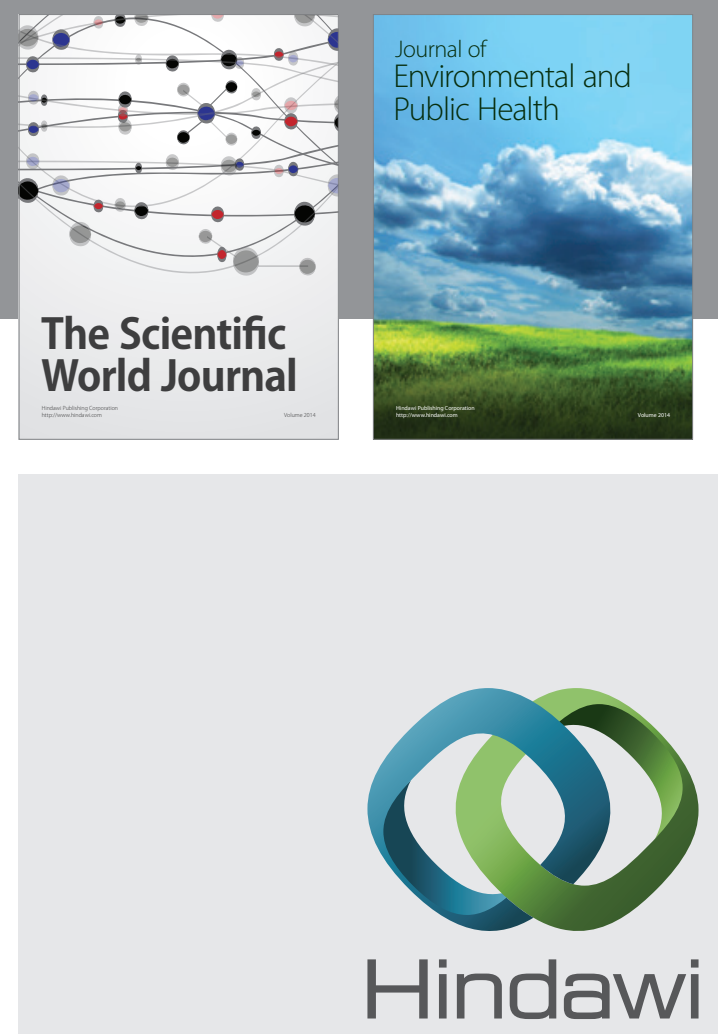

Submit your manuscripts at

http://www.hindawi.com
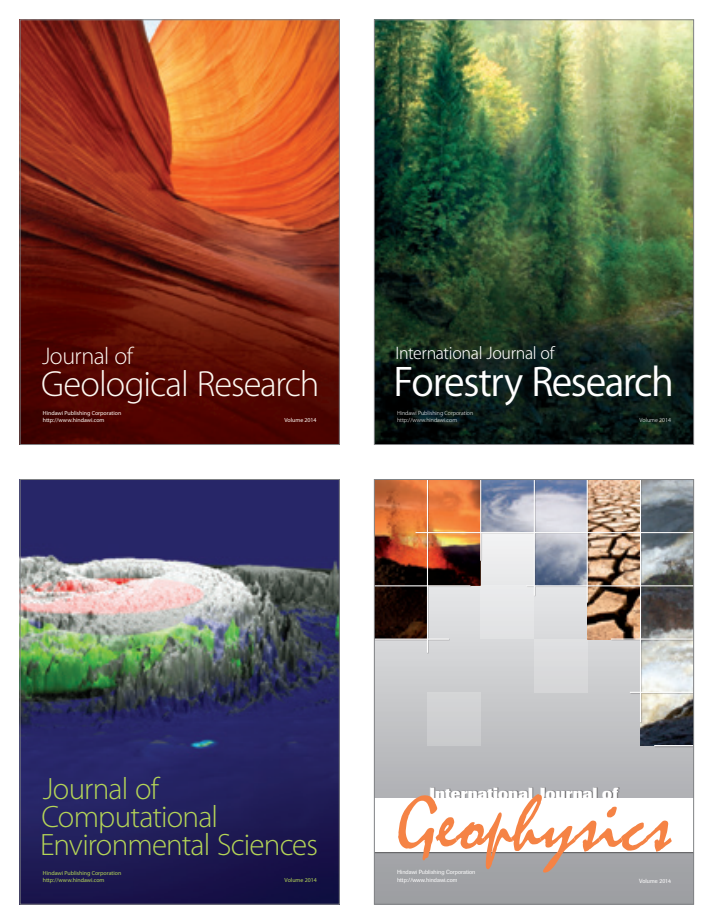
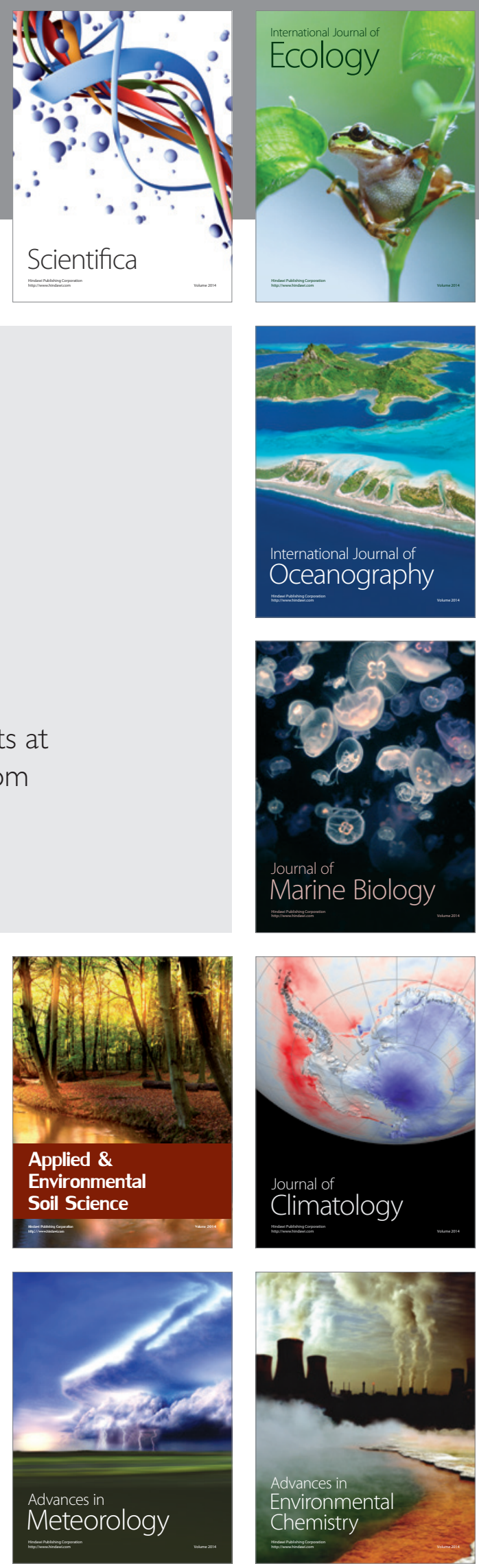